\title{
Correction to: Electrocatalytic oxidation and amperometric determination of hydrazine using a carbon paste electrode modified with $\beta$-nickel hydroxide nanoplatelets
}

\author{
Armen Avanes ${ }^{1} \cdot$ Mohammad Hasanzadeh-Karamjavan $^{1} \cdot$ Golnaz Shokri-Jarcheloo $^{1}$
}

Published online: 9 July 2019

C) Springer-Verlag GmbH Austria, part of Springer Nature 2019

Correction to: Microchimica Acta (2019) 186:441

https://doi.org/10.1007/s00604-019-3555-x

The authors of "Electrocatalytic oxidation and amperometric determination of hydrazine using a carbon paste electrode modified with $\beta$-nickel hydroxide nanoplatelets (Microchimica Acta (2019) 186:441)" wish to update the incorrect panel/labels of Fig. 3. Unfortunately in the online version of the article, Fig. 3 has four parts which should be labeled as $\mathbf{a}, \mathbf{b}, \mathbf{c}$, and $\mathbf{d}$; but were incorrectly labeled as $\mathbf{a}, \mathbf{b}, \mathbf{d}$, and $\mathbf{d}$. There are two "d" in and no "c". The correct image is given in this article.

The original article has been corrected.

Publisher's note Springer Nature remains neutral with regard to jurisdictional claims in published maps and institutional affiliations.

The online version of the original article can be found at https://doi.org/ 10.1007/s00604-019-3555-x

Armen Avanes

armen.avanes@gmail.com

Department of Chemistry, Faculty of Science, University of Maragheh, Maragheh 55181-83111, Iran 

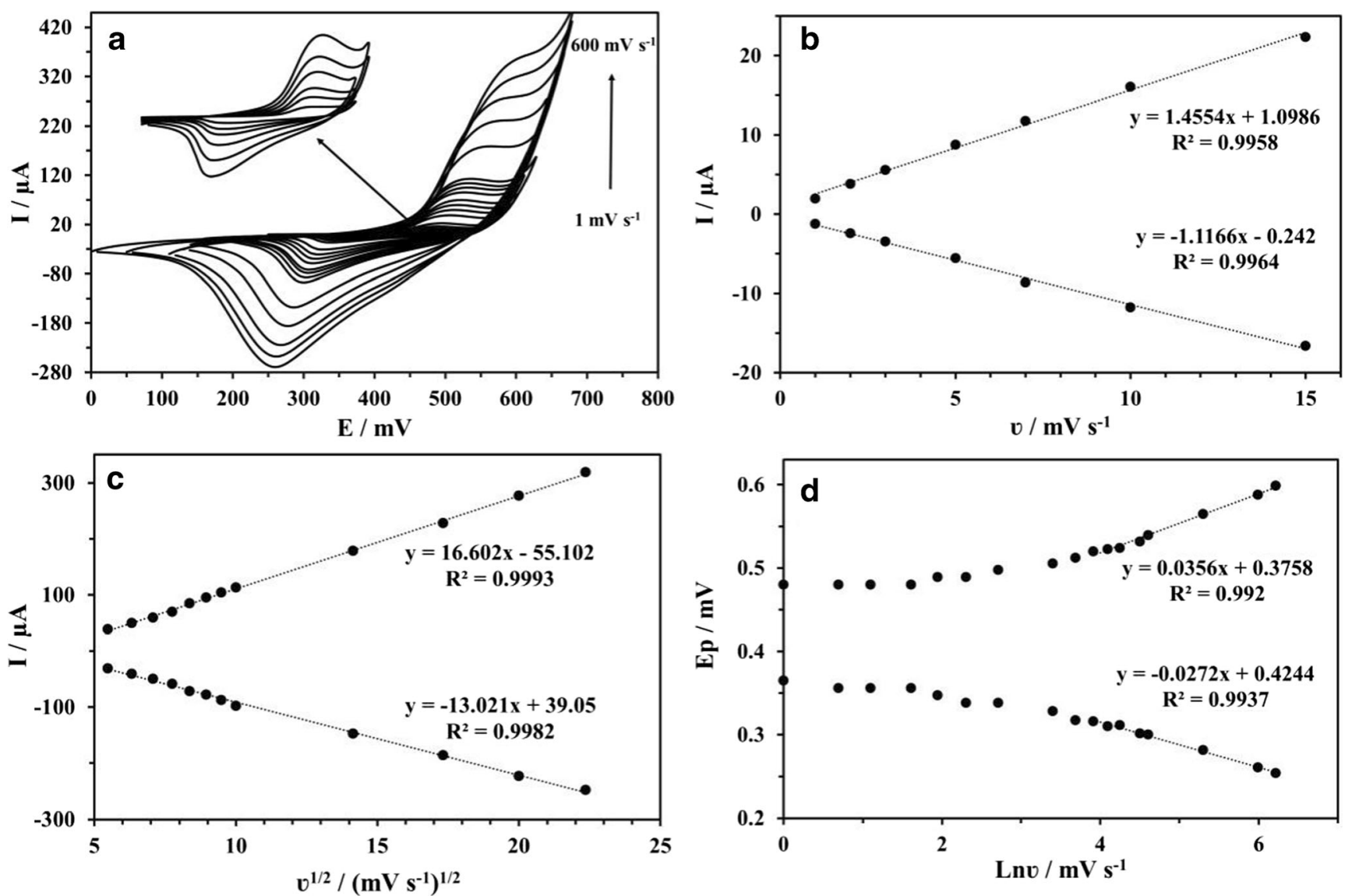

Fig. 3 a Cyclic voltammograms of NP-CPE recorded at different potential sweep rates of 1-600 $\mathrm{mV} \mathrm{s}^{-1}$. b Linear dependency of anodic and cathodic peak currents on the potential sweep rates at values lower than $20 \mathrm{mV} \mathrm{s}^{-1}$. $\mathbf{c}$ Dependency of anodic and cathodic peak currents on

the square root of the potential sweep rate at high values of $\geq 30 \mathrm{mV} \mathrm{s}^{-1} \mathbf{d}$ Variation of the anodic and cathodic peak potentials with the natural logarithm of the potential sweep rate 